\section{Successful treatment of acute gastric volvulus by emergency endoscopic reduction in a patient with cerebral palsy}

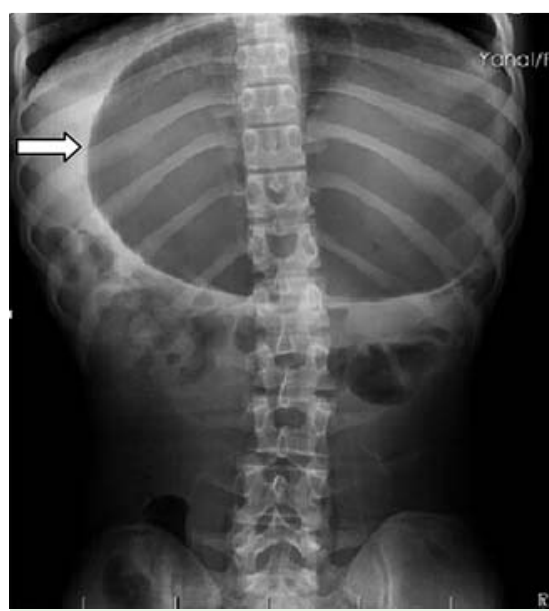

Fig. 1 Supine abdominal radiograph showing a grossly dilated stomach (white arrow).

A 25-year-old man with mixed dystonic/ spastic cerebral palsy was admitted to our emergency department with a 12hour history of severe abdominal pain, abdominal distension, and retching. His medical history was otherwise unremarkable. Physical examination revealed a distended, tympanic mass in the left upper quadrant and epigastric region. The results of laboratory investigations were unremarkable.

A supine abdominal plain radiograph revealed a grossly dilated stomach ( Fig.1). An abdominal computed tomography (CT) scan also showed marked distension of the stomach, which was compressing the second part of the duodenum; the first part of the duodenum was not seen ( Fig. 2 ). These findings were thought to represent a mesenteroaxial gastric volvulus.

An immediate surgical operation was considered but a palliative approach was agreed on with the man's parents because of the high risk of surgery. Therefore, an upper gastrointestinal endoscopy was performed, which revealed a normallooking esophagus and a distended stomach that was filled with gastric secretions ( Fig.3). After aspiration of over $3 \mathrm{~L}$ of liquid, we saw a peculiar gastric anatomy resembling cascade stomach. It was not possible initially to pass the endoscope through the pylorus. With various endo-

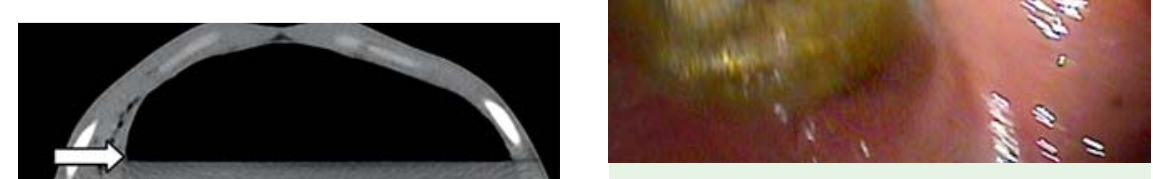

Fig.3 Upper gastrointestinal endoscopy showing the dilated stomach containing residual food and fluid.

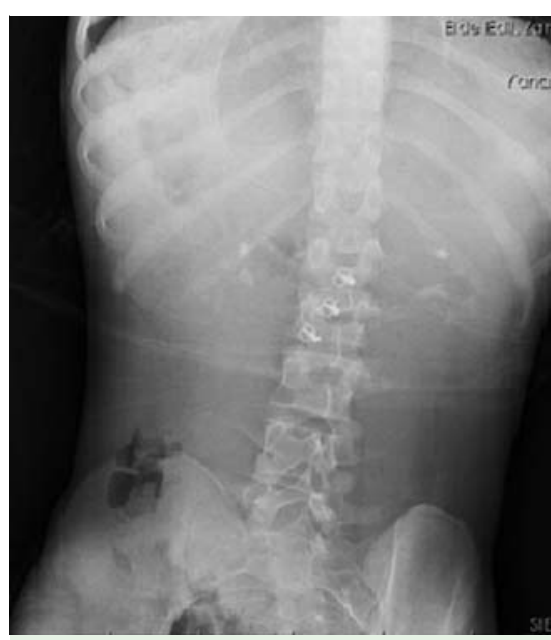

Fig.4 Supine abdominal radiograph after endoscopic reduction of the volvulus showing normalization of the appearance of the stomach.

Acute gastric volvulus is a rare acute surgical emergency that involves abnormal rotation of the stomach along one of its axes by more than $180^{\circ}$ [1]. Gastric volvulus can be classified into either organo-axial or mesentero-axial types. Most of the reported cases are secondary to paraesophageal hernias or a diaphragmatic defect, and primary mesentero-axial vol-

In our patient, cerebral palsy and related postural deformity may have caused imbalance of the normal tensions between the ligamentous attachments of the stomach, resulting in a mesentero-axial gastric volvulus. In the emergency setting, the option of endoscopic decompression and reduction should be kept in mind in order to reduce the morbidity and mortality that is associated with emergency surgery vulus is rare. [2]. gastric volvulus with a further abdominal radiograph ( $\bullet$ Fig.4).

scopic maneuvers, such as clockwise rotation and pulling back of the endoscope to the proximal stomach using a J-type maneuver, we succeeded in passing the endoscope through the pylorus into the duodenum. The patient's symptoms were relieved and his subsequent course was uneventful. We confirmed resolution of the radiograph (Q Fig.4).
Fig. 2 Computed tomography (CT) scan images showing: a marked distension of the distension of the stomach and compression arrow) in coronal view.

Endoscopy_UCTN_Code_TTT_1AO_2AN

Competing interests: None 


\section{Serta Kılınçalp, Hakan Akinci,} Şahin Çoban

Department of Gastroenterology, Diskapi Yildirim Beyazit Education and Research Hospital, Ankara, Turkey

\section{References}

1 Wasselle JA, Norman J. Acute gastric volvulus: pathogenesis, diagnosis, and treatment. Am J Gastroenterol 1993; 88: 1780 - 1784

2 Kulkarni K, Nagler J. Emergency endoscopic reduction of a gastric volvulus. Endoscopy 2007; 39 (Suppl. 01): E173
Bibliography

Dol http://dx.doi.org/

10.1055/s-0034-1377350

Endoscopy 2014; 46: E375-E376

(c) Georg Thieme Verlag KG

Stuttgart · New York

ISSN 0013-726X
Corresponding author

Şahin Çoban, MD

Çukurambar Mah. Ogretmenler Cd. 23/15

Çankaya

Ankara, 06520

Turkey

scoban72@yahoo.com 